\title{
Effects of Pressure on the Performance of
}

\section{CNTs-Supported Catalyst in a Fischer-Tropsch Reaction}

\author{
Noor Asmawati Mohd Zabidi ${ }^{1}$, Sardar $\mathrm{Ali}^{2}$ and Duvvuri Subbarao ${ }^{2}$ \\ 1. Department of Fundamental and Applied Sciences, Universiti Teknologi PETRONAS, Bandar Seri Iskandar, Tronoh 31750, Perak, \\ Malaysia \\ 2. Department of Chemical Engineering, Universiti Teknologi PETRONAS, Bandar Seri Iskandar, Tronoh 31750, Perak, Malaysia
}

Received: January 10, 2014 / Accepted: January 31, 2014 / Published: February 25, 2014.

\begin{abstract}
Fischer-Tropsch (FT) reaction involves conversion of syngas (a mixture of carbon monoxide and hydrogen) into higher hydrocarbons in the presence of an active catalyst. The syngas can be derived from non-petroleum feedstocks such as coal, biomass and natural gas, thus the FT reaction provides an alternative route for production of clean fuels. The FT process has received growing interest in recent years due to uncertainty in the Middle East, fast depletion of fossil fuel and environmental concern. This paper reports the synthesis, physicochemical properties and catalytic performance of cobalt-based catalyst in the FT reaction. The catalysts comprised metal nanoparticles supported on carbon nanotubes (CNTs) which were synthesized via a wet impregnation method. The catalysts were characterized using transmission electron microscopy (TEM), temperature-programmed reduction/desorption (TPR/TPD) and X-ray photoelectron spectroscopy (XPS). The performance of the cobalt-based catalyts in a FT reaction was evaluated in a fixed bed microreactor equipped with an on-line gas chromatograph for analyses of hydrocarbon products. The catalysts investigated in this work were Co/CNTs, $70 \mathrm{Co} 30 \mathrm{Mn} / \mathrm{CNTs}, 0.06 \% \mathrm{~K} / 70 \mathrm{Co} 30 \mathrm{Fe} / \mathrm{CNTs}$ and $0.04 \% \mathrm{Nb} / 70 \mathrm{Co} 30 \mathrm{Fe} / \mathrm{CNTs}$. TEM analyses revealed that the average sizes of the metal nanoparticles were 4-5 nm. Based on TPD analyses, the dispersion of these nanoparticles on CNTs were greater than $90 \%$. The presence of both $\mathrm{Co}^{2+}$ and $\mathrm{Co}^{3+}$ ions were confirmed by XPS analysis. The $0.04 \% \mathrm{Nb} / 70 \mathrm{Co} 30 \mathrm{Fe} / \mathrm{CNTs}$ catalyst performed better than other catalysts in the FT reaction where it resulted in CO conversion of $35 \%$ and $16 \% \mathrm{C}_{5+}$ selectivity at pressure of 1 bar, $220{ }^{\circ} \mathrm{C}$ and $\mathrm{H}_{2}: \mathrm{CO}$ of $2: 1$. Using the same catalyst, the $\mathrm{CO}$ conversion and $\mathrm{C}_{5+}$ selectivity increased to $60 \%$ and $57 \%$, respectively when the pressure was increased to 20 bar.
\end{abstract}

Key word: Fischer-Tropsch, catalyst, cobalt, fuels.

\section{Introduction}

Fischer-Tropsch (FT) synthesis is a process which deals with the chemical conversion of syngas (a mixture of carbon monoxide and hydrogen) derived from coal, biomass and natural gas into hydrocarbons consisting of paraffins, olefins, alcohols and aldehydes [1]. Due to uncertainty in the Middle East, limited petroleum reserves and environmental restrictions, FT reaction is gaining more attention nowadays than ever. Fischer-Tropsch synthesis is

Corresponding author: Noor Asmawati Mohd Zabidi, Ph.D., associate professor, research fields: Fischer-Tropsch catalysis, $\quad \mathrm{CO}_{2} \quad$ hydrogenation. E-mail: noorasmawati_mzabidi@petronas.com.my. considered as a surface-catalyzed polymerization reaction which provides an alternative route for production of clean fuels from non-petroleum source. Cobalt and iron-based catalysts are the most widely used catalysts in the FT reaction. Tavasoli et. al. [2] discovered that the combination of the two most active catalysts, $\mathrm{Fe}$ and $\mathrm{Co}$, enhanced the selectivity to alcohols and olefins. It has also been reported that $\mathrm{TiO}_{2}$-supported Co-Mn catalyst enhanced the selectivity to higher olefins and middle distillate [3]. Arsalanfar and co-workers [1] recently reported the kinetics and mechanism of Fe-Co-Mn system at temperature range of $290-320{ }^{\circ} \mathrm{C}$ and reaction pressure of 1-10 bar. Their findings show that the $\mathrm{C}_{5+}$ 
selectivity was enhanced with increasing reaction pressure. They also derived kinetic expressions based on the Langmuir-Hinshelwood-Hougen-Watson mechanism where one of the possibility involved associative $\mathrm{CO}$ adsorption on the surface of the transition metal and then hydrogenated producing $\mathrm{CH}_{\mathrm{x}}$ monomers which consequently propagate to produce hydrocarbons and oxygenates with a broad range of functionalities and chain lengths.

Gauba and Klein [4] reported that promoters such as $\mathrm{Na}, \mathrm{Li}, \mathrm{K}$ and $\mathrm{Cs}$ increased alkene selectivity and chain growth probability on the iron and cobalt FT catalysts. The application of $\mathrm{K}$ as a promoter was found to inhibit the FTS activity drastically while $\mathrm{Zr}$ promoter improved the FTS activity significantly due to increase in the surface acidity and heat of adsorption of $\mathrm{H}_{2}$ on Co catalyst [5]. The effect of $\mathrm{Nb}$ as a promoter on CNTs-supported Co-based catalyst has not been reported in the literature. This paper reports the characterization and performance studies of cobalt-based catalyst in a FT reaction. The catalysts tested include monometallic Co and bimetallic Co catalysts promoted with $\mathrm{Nb}$ and $\mathrm{K}$. The effects of operating pressure on the $\mathrm{CO}$ conversion, $\mathrm{CH}_{4}$ selectivity and $\mathrm{C}_{5+}$ hydrocarbons selectivity over various Co-based catalysts are presented.

\section{Experiments}

Prior to metal loading carbon nanotubes (CNTs), (purity $>95 \%$, length: $10-50 \mu \mathrm{m}$, diameter: $10-25 \mathrm{~nm}$, ILJIN Nanotech Co., Ltd) were functionalized and activated. In this process, required amount of CNTs were treated with $35 \mathrm{vol} \% \mathrm{HNO}_{3}$ (65vol\%, Merck) for $16 \mathrm{~h}$ at $110^{\circ} \mathrm{C}$ followed by washing with deionized water until the $\mathrm{pH}$ was neutral and drying overnight at $120{ }^{\circ} \mathrm{C}$. Catalysts were prepared using a wet impregnation method with $5 \mathrm{wt} \%$ metal loading on CNTs. For each catalyst, required amounts of the precursor salts i.e. $\mathrm{Co}\left(\mathrm{NO}_{3}\right)_{2} \cdot 6 \mathrm{H}_{2} \mathrm{O}(\geq 98 \%$, Fluka) and $\mathrm{Mn}\left(\mathrm{NO}_{3}\right)_{2} \cdot 4 \mathrm{H}_{2} \mathrm{O}(\geq 99.0 \%$, Merck) were dissolved in deionized water and added to the support drop-wise with constant stirring followed by drying at $120{ }^{\circ} \mathrm{C}$ overnight and calcining at $500{ }^{\circ} \mathrm{C}$ in nitrogen atmosphere for 6 hours. Bimetallic catalysts, namely $\mathrm{Co}-\mathrm{Fe}$ and $\mathrm{Co}-\mathrm{Mn}$ systems were prepared via co-impregnation method. The catalysts were promoted by adding solutions of niobium nitrate or potassium nitrate to the dried catalysts.

The TPR/TPO/TPD profiles of the catalysts were investigated using TPDRO1100 MS (CE Instruments) equipped with a thermal conductivity detector and a mass spectrometer. Typically $20 \mathrm{mg}$ catalyst was placed in the U-shaped quartz tube. Catalyst samples were degassed in a flow of nitrogen at $200{ }^{\circ} \mathrm{C}$. $\mathrm{H}_{2}$-TPR was performed using $5 \% \mathrm{H}_{2} / \mathrm{N}_{2}$ with a flow rate of $20 \mathrm{~cm}^{3} \cdot \mathrm{min}^{-1}$ and heating from $40{ }^{\circ} \mathrm{C}$ to $800{ }^{\circ} \mathrm{C}$ at $10{ }^{\circ} \mathrm{C} \cdot \mathrm{min}^{-1}$. For $\mathrm{H}_{2}-\mathrm{TPD}$, the sample was reduced under $\mathrm{H}_{2}$ flow at $370{ }^{\circ} \mathrm{C}$ for $6 \mathrm{~h}$, cooled to $40{ }^{\circ} \mathrm{C}$ under $\mathrm{H}_{2}$ flow, flushed with $\mathrm{He}$ to remove physisorbed $\mathrm{H}_{2}$ and then heated to $400{ }^{\circ} \mathrm{C}$ under $\mathrm{He}$ flow at $10{ }^{\circ} \mathrm{C} \mathrm{min}^{-1}$ for $3 \mathrm{~h} . \mathrm{H}_{2}$-TPD analysis was used to calculate the degree of dispersion of the catalysts and results of TPO analyses were used to calculate the degree of reduction of the catalyst. The CO chemisorption was conducted after the $\mathrm{H}_{2}$-TPD by introducing pulses of $\mathrm{CO}$ at $250{ }^{\circ} \mathrm{C}$ until the TCD signal was constant.

Morphology of the catalyst samples was characterized using transmission electron microscopy (Zeiss LIBRA 200 TEM at $200 \mathrm{kV}$ ). X-ray photoelectron spectra were obtained from K-Alpha spectrometer (Thermo Scientific) at $50 \mathrm{eV}$ pass energy. Fischer-Tropsch reaction was performed in a fixed-bed microreactor (Microreactivity-Reference, PID, Eng \& Tech) at $\mathrm{T}=220^{\circ} \mathrm{C}, \mathrm{P}=1$ and 20 bar, and $\mathrm{H}_{2} / \mathrm{CO}=2 \mathrm{v} / \mathrm{v}$. Catalyst sample $(40 \mathrm{mg})$ was reduced in-situ at $653 \mathrm{~K}$ for $5 \mathrm{~h}$ in $30 \mathrm{ml} \cdot \mathrm{min}^{-1}$ of pure hydrogen. On-line gas analysis was performed using Agilent 6890 Hewlett Packard (HP) gas chromatograph (GC) equipped with TCD and FID detectors. Hydrocarbons were separated by the $\mathrm{GC}-\mathrm{Al} / \mathrm{KCl}$ column while other gases were separated 
by the serially connected HP-Plot $U$ and HP-Molesieve columns.

\section{Experimental Results}

\subsection{Physicochemical Properties}

Fig. 1 shows the TEM of the 70Co30Mn catalyst on CNTs support. Most of the nanoparticles were deposited in the inner walls of the CNTS. The average size of the nanoparticles was $5 \pm 2 \mathrm{~nm}$.

The properties of the catalysts are revealed in Table 1. The incorporation of $\mathrm{Fe}$ and $\mathrm{Mn}$ into $\mathrm{Co}$ increased the reducibility, dispersion and $\mathrm{CO}$ adsorption capacity of the Co catalyst. However, both $\mathrm{K}$ and $\mathrm{Nb}$ promoters were found to decrease the reducibility of Co possibly due to electronic modification of the Co which resulted in an increase in $\mathrm{CoO}$ phase, as revealed by the XPS studies. The presence of $\mathrm{CoO}$ could also contribute to the lower degree of reduction for the promoted $70 \mathrm{Co} 30 \mathrm{Fe}$ catalyst. Nevertheless, the presence of both $\mathrm{K}$ and $\mathrm{Nb}$ promoters enhanced the dispersion and the $\mathrm{CO}$ adsorption capacity of the Co-based catalyst.

Fig. 2 shows the XPS spectrum of $\mathrm{Co} 2 \mathrm{p}$ region of the un-promoted and $\mathrm{Nb}$-promoted $\mathrm{Co}-\mathrm{Fe}$ catalyst and the detailed results of XPS are shown in Table 2.

The F30 sample shows an asymmetric main peak of $\mathrm{Co} 2 \mathrm{p}_{3 / 2}$ at $780.4 \mathrm{eV}$ and a satellite peak at $788.3 \mathrm{eV}$. The $\mathrm{Co}_{3} \mathrm{O}_{4}$ compound contains $\mathrm{Co}^{3+}$ in octahedral symmetry and $\mathrm{Co}^{2+}$ in tetrahedral symmetry with binding energy at 779.5 and $780.3 \mathrm{eV}$, respectively [6]. It has been reported that the presence of a satellite peak at binding energy (BE) around $6 \mathrm{eV}$ above the main peak $\mathrm{Co} 2 \mathrm{p}_{3 / 2}$ is a characteristic of the octahedrally-coordinated high-spin $\mathrm{Co}^{2+}$ oxides $(\mathrm{CoO})$ [7]. In this work, the satellite peak was detected at $\mathrm{BE}$ higher than $6 \mathrm{eV}$, presumably due to difference in support material and electronic modification due to incorporation of a second metal into the Co-based catalyst. The octahedral $\mathrm{Co}^{3+}$ and tetrahedral $\mathrm{Co}^{2+}$ peaks were not completely resolved in the XPS spectra due to small difference in $\mathrm{BE}$ between $\mathrm{Co}^{3+}$ (octahedral) and $\mathrm{Co}^{2+}$ (tetrahedral) ions. However, the asymmetric $\mathrm{Co} 2 \mathrm{p}_{3 / 2}$ peak suggests that the main peak was due to presence of both $\mathrm{Co}^{3+}$ (octahedral) and $\mathrm{Co}^{2+}$ (tetrahedral) ions. Results of XPS show that the monometallic $\mathrm{Co}$ only contained $\mathrm{Co}_{3} \mathrm{O}_{4}$ phase whereas the bimetallic $\mathrm{Co}-\mathrm{Fe}$ and the promoted catalysts also contained $\mathrm{CoO}$ phase, as evidenced by the presence of the satellite peak. The ratios of satellite peak $\left(\mathrm{Co}^{2+}\right)$ to the main $\mathrm{Co} 2 \mathrm{p}_{3 / 2}$ peak $\left(\mathrm{Co}^{3+}\right)$ varied with incorporation of a second metal and a promoter. The highest $\mathrm{Co}^{2+} / \mathrm{Co}^{3+}$ ratio was obtained from $\mathrm{Nb}$-promoted $70 \mathrm{Co} 30 \mathrm{Fe}$ catalyst which also showed the highest catalytic activity.

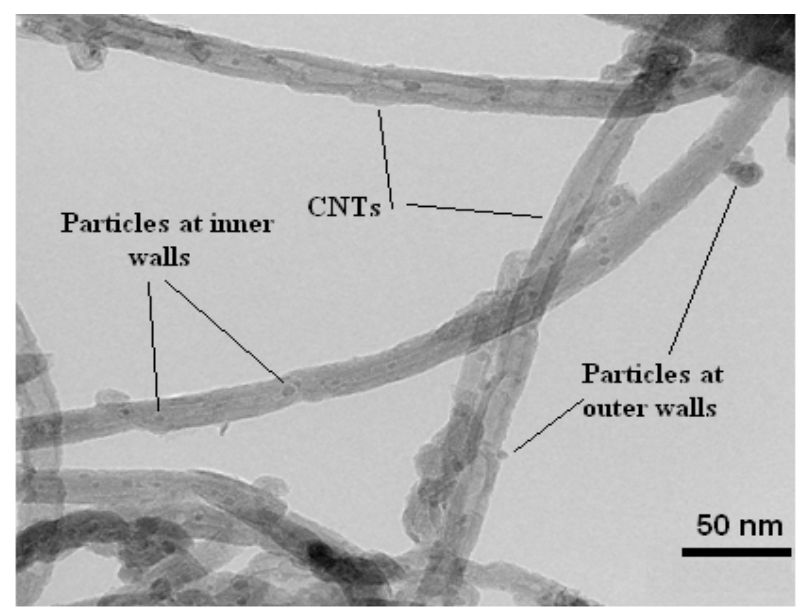

Fig. 1 TEM image of $70 \mathrm{Co30Mn} / \mathrm{CNTs}$.

Table 1 Results of chemisorption studies on CNTs-supported catalysts.

\begin{tabular}{lllll}
\hline Code & Catalyst & $\mathrm{R}^{*}(\%)$ & $\mathrm{D}^{*}(\%)$ & CO ads $(\mu \mathrm{mol} / \mathrm{gcat})$ \\
\hline Co & Co & 56.2 & 73.5 & 9.0 \\
F30 & $70 \mathrm{Co} 30 \mathrm{Fe}$ & 62.2 & 90.4 & 13.2 \\
F30K1 & $0.06 \% \mathrm{~K} / 70 \mathrm{Co} 30 \mathrm{Fe}$ & 44.1 & 96.7 & 15.6 \\
F30Nb2 & $0.04 \% \mathrm{Nb} / 70 \mathrm{Co} 30 \mathrm{Fe}$ & 42.8 & 96.3 & 20.7 \\
N30 & $70 \mathrm{Co} 30 \mathrm{Mn}$ & 62.2 & 94.8 & 17.8 \\
\hline
\end{tabular}

$\mathrm{R}^{*}$ is the reduction (\%) and $\mathrm{D}^{*}$ is the dispersion. 


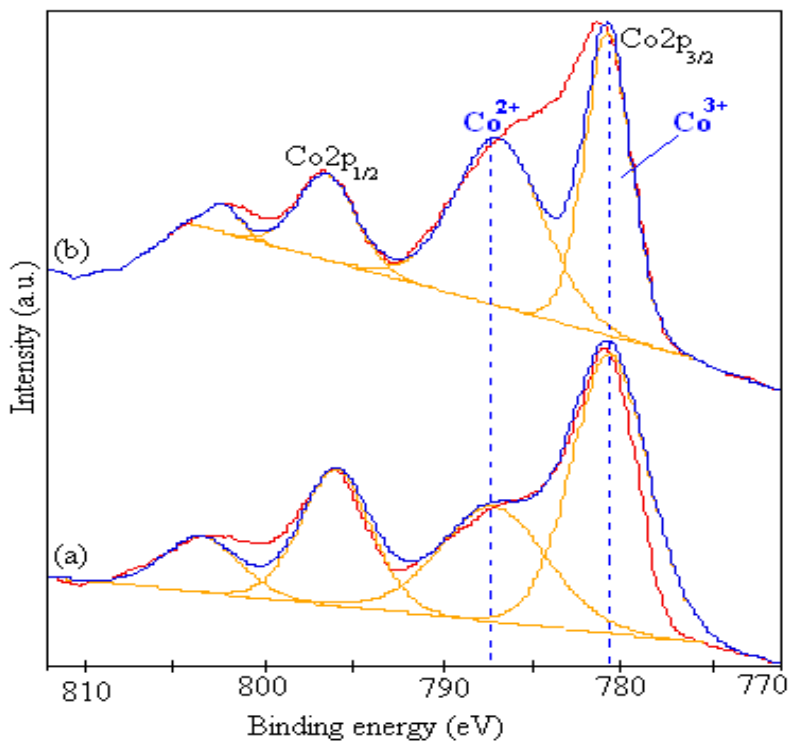

Fig. 2 XPS Co2p spectra (a) F30 (b) F30Nb2.

Table 2 Results of XPS analyses.

\begin{tabular}{llll}
\hline Code & $\begin{array}{l}\mathrm{BE}(\mathrm{eV}) \\
\mathrm{Co} 2 \mathrm{p}_{3 / 2}\end{array}$ & $\begin{array}{l}\mathrm{BE}(\mathrm{eV}) \\
\mathrm{Fe} 2 \mathrm{p}_{3 / 2}\end{array}$ & $\begin{array}{l}\text { Peak ratio } \\
\mathrm{Co}^{2+} / \mathrm{Co}^{3+}\end{array}$ \\
\hline Co & 780.6 & - & 0.19 \\
F30 & 780.4 & 711.3 & 0.83 \\
F30K1 & 780.6 & 711.3 & 0.76 \\
F30Nb2 & 780.2 & 711.6 & 2.4 \\
N30 & 780.1 & - & 0.7 \\
\hline
\end{tabular}

\subsection{Catalytic Activities}

Figs. 3-5 show the effects of pressure on the $\mathrm{CO}$ conversion, $\mathrm{CH}_{4}$ and $\mathrm{C}_{5+}$ selectivities, respectively.

The CO conversion over Co, F30K1 $(0.06 \% \mathrm{~K} / 70 \mathrm{Co} 30 \mathrm{Fe}), \mathrm{F} 30 \mathrm{Nb} 2(0.04 \% \mathrm{Nb} / 70 \mathrm{Co} 30 \mathrm{Fe})$ and N30 (70Co30Mn) catalysts at 20 bar operating pressure was increased by $27.3 \%, 55.9 \%, 59.6 \%$ and $38.5 \%$, respectively, compared to those of at 1 bar. This trend agreed with those reported in the literature where it has been suggested that increase in operating pressure increased the concentration of the reactant species over the active sites of the catalysts and hence CO conversion increased. This could also be attributed to increase in adsorption of $\mathrm{CO}$ molecules on the surface of the catalysts and improved collision probability of reactants and catalyst [7]. The CO conversion correlated well with the catalyst properties.

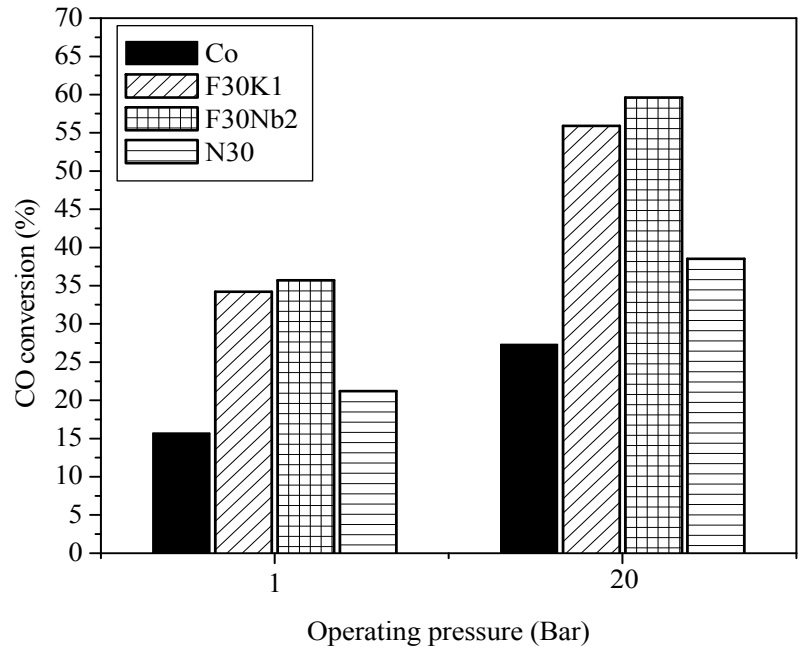

Fig. 3 Effects of operating pressure on CO conversions.

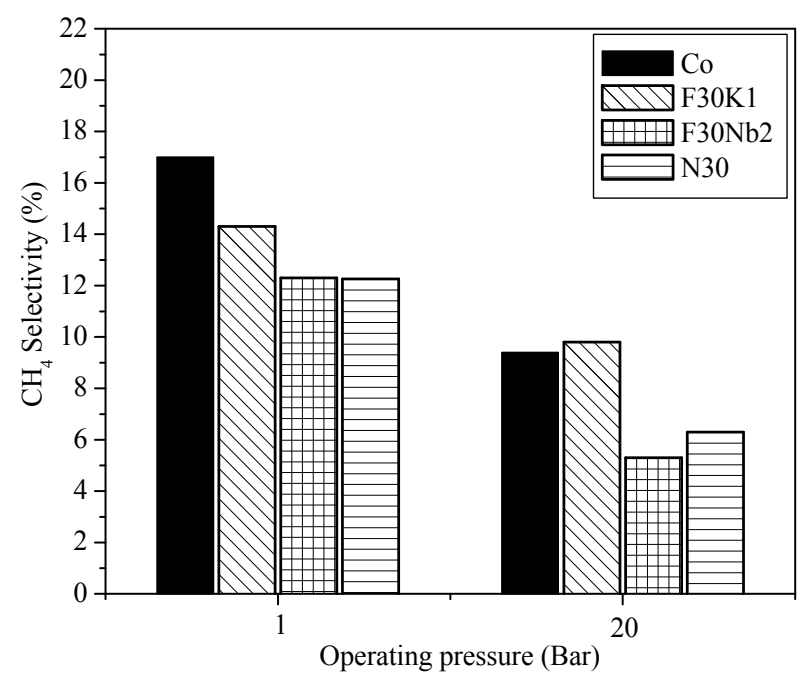

Fig. 4 Effects of operating pressure on $\mathrm{CH}_{4}$ selectivity.

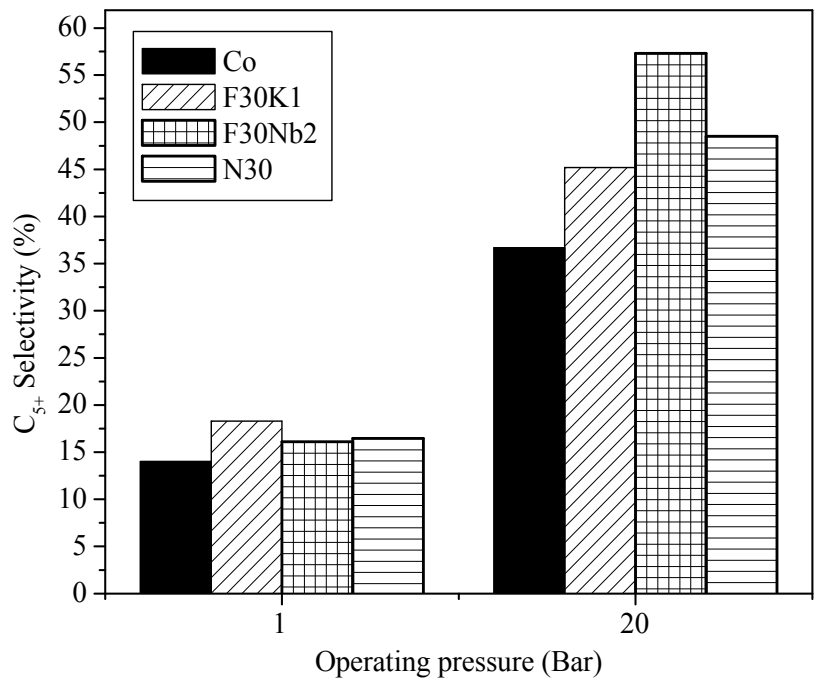

Fig. 5 Effects of operating pressure on $\mathrm{C}_{5^{+}}$selectivity. 
Amongst the catalysts tested, the Nb-promoted Fe-Co bimetallic system (F30Nb2) exhibited high dispersion, largest $\mathrm{CO}$ adsorption capacity and highest ratio of $\mathrm{Co}^{2+} / \mathrm{Co}^{3+}$ thus exhibited highest catalytic activity.

Fig. 4 shows that selectivity to $\mathrm{CH}_{4}$ (undesired product) was suppressed at higher operating pressure while Fig. 5 revealed that increasing the pressure to 20 bar increased the selectivity of $\mathrm{C}_{5+}$ hydrocarbons (desired products). This effect was more pronounced for the $\mathrm{Nb}$-promoted catalyst $(\mathrm{F} 30 \mathrm{Nb} 2)$ where $\mathrm{C}_{5+}$ selectivity increased from $16.1 \%$ to $57.3 \%$. It has been proposed that with increase in the operating pressure the chain growth probability increased which consequently favored selectivities to higher hydrocarbons [8]. Fernandes and Sousa [9] has also reported that an increase in operating pressure would generally increase the chain propagation of $\mathrm{CH}_{\mathrm{X}}$ monomers onto the active surfaces of the catalysts and hence increase selectivities for higher hydrocarbons. The values for $\mathrm{CO}$ conversion and $\mathrm{C}_{5+}$ selectivity were lower than those reported by Tavasoli et al. [2] where they have reported $\mathrm{CO}$ conversion of $47 \%$ and $\mathrm{C}_{5+}$ selectivity of $85.1 \%$ using $10 \% \mathrm{Co} / \mathrm{CNTs}$ catalyst under similar operating conditions. However, the $\mathrm{CH}_{4}$ selectivity obtained from this work was similar to value reported by them, which was $9.3 \%$. The higher $\mathrm{CO}$ conversion and $\mathrm{C}_{5+}$ selectivity could be due to higher Co loading than the one used in this work.

\section{Conclusions}

Co-based catalysts with different formulations were supported on CNTs. The incorporation of a second metal improved the degrees of reducibility and dispersion of the catalysts. Results of XPS confirmed that promoters ( $\mathrm{K}$ and $\mathrm{Nb})$ caused electronic modification in the Co-based catalyst. The performance of the catalysts was evaluated in a Fischer-Tropsch reaction. Amongst the catalysts tested, the $\mathrm{Nb}$-promoted $\mathrm{Co}-\mathrm{Fe}$ catalyst showed the highest catalytic activity and selectivity of $\mathrm{C}_{5+}$ hydrocarbons (desired products). Increasing the pressure from 1 to 20 bar enhanced both the $\mathrm{CO}$ conversion and $\mathrm{C}_{5+}$ hydrocarbon selectivity (desired products) while the $\mathrm{CH}_{4}$ selectivity (undesired product) was suppressed.

\section{Acknowledgments}

The authors gratefully acknowledge the contribution from Ministry of Science, Technology and Innovation (E-Science Fund No: 03-02-02-SF0036), Ministry of Higher Education Malaysia (FRGS No: FRGS /2/2010/SG/UTP/02/3, FRGS/1/2012/SG01/ UTP/02/ 1) and Universiti Teknologi PETRONAS.

\section{Reference}

[1] M. Arsalanfar, A.A. Mirzaei, H. Atashi, H.R. Bozorgzadeh, S. Vahid, A.M. Zare, An investigation of the kinetics and mechanism of Fischer-Tropsch synthesis on Fe-Co-Mn supported catalyst, Fuel Processing Technology 96 (2012) 150-159.

[2] A. Tavasoli, M. Trepanier, R.M. Malek Abbaslou, A.K. Dalai, N. Abatzoglou, Fischer-Tropsch synthesis on mono-and bimetallic $\mathrm{Co}$ and $\mathrm{Fe}$ catalyst supported on carbon nanotubes, Fuel Processing Technology 90 (2009)1486-1494.

[3] T.E. Feltes, L. Espinosa-Alonso, E. de Smit, L. D’Souza, R.J. Meyer, B.M. Weckhuysen, et al., Selective adsorption of manganese onto cobalt for optimized $\mathrm{Mn} / \mathrm{Co} / \mathrm{TiO}_{2}$ Fischer-Tropsch catalysts, Journal Catalysis 270 (2010) 95-102.

[4] H. Gaube, H.F. Klein, The promoter effect of alkali in Fischer-Tropsch iron and cobalt catalysts, Applied Catalysis A 350 (2008) 126-132.

[5] L. Chen, G. Song, Y. Fu, J. Shen, The effects of promoters of $\mathrm{K}$ and $\mathrm{Zr}$ on the mesoporous carbon supported cobalt catalysts for Fischer-Tropsch synthesis, Journal of Colloid and Interface Science 368 (2012) 456-461.

[6] G. Jacobs, J.A. Chaney, P.M. Patterson, T.K. Das, B. Davis, Fischer-Tropsch synthesis: Study of the promotion of $\mathrm{Re}$ on the reduction property of $\mathrm{Co} / \mathrm{Al}_{2} \mathrm{O}_{3}$ catalysts by in situ EXAFS/XANES of Co $\mathrm{K}$ and Re $\mathrm{L}_{\mathrm{III}}$ edges and XPS, Applied Catalysis A 264 (2004) 203-212.

[7] S.C. Petitto, E.M. Marsh, G.A. Carson, M.A. Langell, Cobalt oxide surface chemistry: The interaction of $\mathrm{CoO}(100), \mathrm{Co}_{3} \mathrm{O}_{4}(110)$ and $\mathrm{Co}_{3} \mathrm{O}_{4}(111)$ with oxygen and water, Journal Molecular Catalysis 281 (2008) 49-58. 
[8] V.A. de la Pena O’Shea, M.C. Alvarez-Galvan, J. Campos-Martin, F.J. Strong, Strong dependence on pressure of the performance of a $\mathrm{Co} / \mathrm{SiO}_{2}$ catalyst in Fischer-Tropsch slurry reactor synthesis, Catalysis
Letters 100 (2005) 105-116.

[9] F.A.N. Fernandes, F.A.N.E.M.M. Sousa, Fischer-Tropsch synthesis product grade optimization in a fluidized bed reactor, AIChE Journal 52 (2006) 2844-2850. 